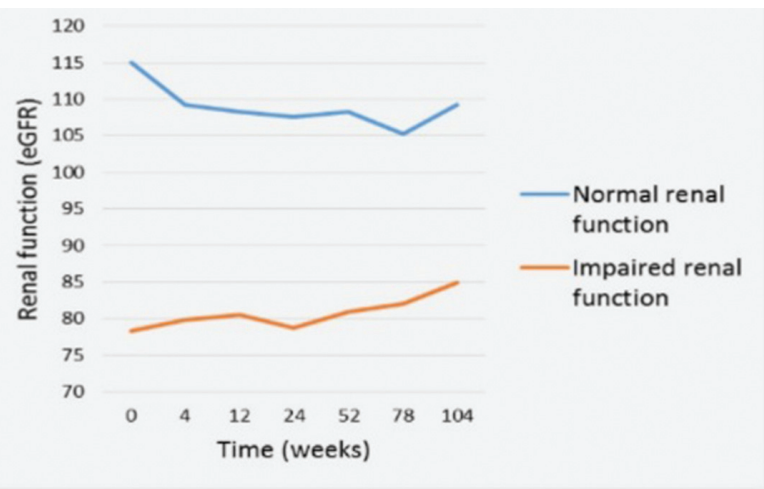

Abstract AB0837 - Figure 1

Conclusions: This study demonstrates that anti-TNF is not associated with renal function in AS patients, which means that use of anti-TNF is safe concerning renal function in patients with AS. From our results it seems that the effect of anti-TNF on CVD in AS patients is not mediated by an effect on renal function.

Disclosure of Interest: None declared

DOI: 10.1136/annrheumdis-2018-eular.6300

\section{AB0838 THE EFFICACY OF ADALIMUMAB AND SULFASALAZINE IN ALLEVIATING AXIAL AND AORTIC INFLAMMATION DETECTED IN PET/CT IN PATIENTS WITH AXIAL SPONDYLOARTHRITIS}

J.-P. Kaijasilta ${ }^{1}$, A. Kerola ${ }^{1}$, R. Tuompo ${ }^{2}$, M. Kauppi ${ }^{3}$, H. Relas ${ }^{2}$, A. Loimaala ${ }^{4}$, H. Koivu ${ }^{5}$, J. Schildt ${ }^{4}$, T. Kerola ${ }^{1}$, K. Eklund ${ }^{2}$, T. Nieminen ${ }^{6} .{ }^{1}$ Internal Medicine, Päijät-Häme Central Hospital, Lahti, ${ }^{2}$ Inflammation Center, Helsinki University Hospital, Helsinki; ${ }^{3}$ Rheumatology, University of Tampere School of Medicine, Tampere; ${ }^{4}$ Medical Imaging Center, Helsinki University Hospital, Helsinki; ${ }^{5}$ Department of Nuclear Medicine, Päijät-Häme Central Hospital, Lahti; ${ }^{6} \mathrm{Heart}$ and Lung Center, Helsinki University Hospital, Helsinki, Finland

Background: Inflammatory pathways are likely the central link from axial spondyloarthritis to the known increased risk of cardiovascular morbidity. Literature on positron emission tomography imaging together with computed tomography (PET/CT) in the context of spondyloarthritis is limited.

Objectives: The aim was to grade the inflammatory signals in the sacroiliac joints and aorta in the PET/CT imaging before and after antirheumatic treatment of clinically active axial spondyloarthritis with either sulfasalazine (SSZ), the firstline antirheumatic drug in Finland for axial spondyloarthritis, or adalimumab (ADA).

Methods: Fourteen patients aged 18-75 years with axial spondyloarthritis and radiologic sacroiliitis as detected either by MRI or X-ray and Bath Ankylosing Spondylitis Disease Activity Index (BASDAI) and visual analogue scale (VAS) $\geq 4$ have been recruited to the pilot study. DMARD-naïve patients started SSZ for 12 weeks. Those who failed to reach remission (BASDAI and VAS $\geq 4$ ) with $S S Z$ or were known to be resistant to conventional DMARDs before inclusion, adalimumab was started for 16 weeks. The patients were scanned with $18 \mathrm{~F}$-fluorodeoxyglucose (FDG) PET/CT after inclusion and after treatment with SSZ and/or ADA. Target-to-background ratio (TBR) was assessed from the aortic root to abdominal aorta as well as for the sacroiliac joints. For statistical comparisons before and after antirheumatic treatment, paired t-test was used. Mean $\pm S D$ are shown.

Results: Our pilot study comprised of nine patients with ADA and five with SSZ. In the SSZ patients (three men, age $36.0 \pm 13.4$ years), mean BASDAI was 4.7 \pm 1.6 before and $3.4 \pm 1.8$ after the treatment $(p=0.091)$. In the ADA patients (six men, age $35.1 \pm 9.8$ years), BASDAl decreased from $4.9 \pm 1.2$ to $2.3 \pm 1.8$ $(p=0.004)$. Among the SSZ patients, maximal TBR in sacroiliac joints declined from $2.35 \pm 0.55$ to $1.51 \pm 0.22(-35.8 \%, p=0.03)$ (figure 1$)$. Aortic maximal TBR declined from $2.44 \pm 0.46$ to $2.07 \pm 0.43(-15.0 \%, p=0.23)$. In the ADA patients, maximal TBR in sacroiliac joints was $1.89 \pm 0.37$ before and $1.90 \pm 0.51$ after treatment $(+0.3 \%, p=0.97)$, and in aorta $2.15 \pm 0.54$ before and $2.37 \pm 0.53$ after treatment $(+10.4 \%, p=0.19)$.

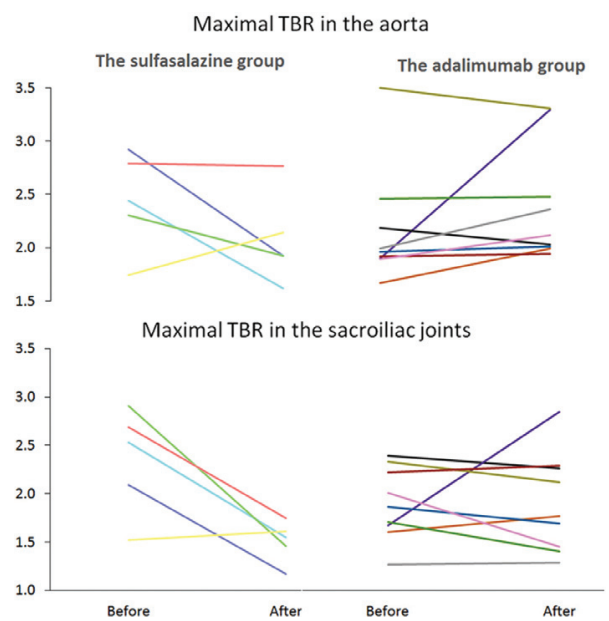

Abstract AB0838 - Figure 1. Maximal TBR in PET/CT in sacroiliac joints and aorta are shown before and after treatment with either sulfasalazine (five patients) or adalimumab (nine patients). Each colour depicts one unique patient.

Conclusions: As detected by reduced 18F-FDG uptake, SSZ reduced inflammation in sacroiliac joints. There was also clear trend towards reduction of inflammation in aorta. ADA and SSZ both reduced clinical symptoms, but only ADA reached statistical significance. PET/CT could not show any reduction in FDG uptake in the ADA group. This may be due to the fact that ADA was used as the second line treatment, when the inflammation had already been reduced to the limit detectable by the method.

Acknowledgements: This study was funded by Abbvie inc.

Disclosure of Interest: J.-P. Kaijasilta: None declared, A. Kerola: None declared, R. Tuompo: None declared, M. Kauppi: None declared, H. Relas: None declared, A. Loimaala: None declared, H. Koivu: None declared, J. Schildt: None declared, T. Kerola: None declared, K. Eklund: None declared, T. Nieminen Grant/research support from: Abbvie Inc

DOI: 10.1136/annrheumdis-2018-eular.4627

\section{AB0839 RADIOLOGIC PARAMETERS OF ANKYLOSING SPONDYLITIS PATIENTS TREATED WITH ANTI-TNF-A VERSUS NON-STEROIDAL ANTI-INFLAMMATORY DRUGS AND SULFASALAZINE}

S.M. Son ${ }^{1}$, J.S. Lee ${ }^{2}$, T.S. Goh², W. Park2 . 'Orthopaedics, Pusan National University Yangsan Hospital, Yangsan; ${ }^{2}$ Orthopaedics, Pusan National University Hospital, Busan, Korea, Republic of Ireland

Background: The introduction of anti-tumour necrosis factor- $\alpha$ (anti-TNF- $\alpha$ ) has significantly altered the treatment landscape of inflammatory arthritis. It has proven to be an excellent treatment option for reducing Ankylosing spondylitis(AS) symptoms. The impact of anti-TNF- $\alpha$ on the radiographic progression of AS has been difficult to characterise, in part because of the relatively slow rate of radiographic change in AS and the hurdles it imposes on longer-term placebo-controlled trials. Despite symptomatic improvement, conclusions concerning effect of anti-TNF- $\alpha$ treatment on radiographic progression in patients with AS remain inconsistent. Furthermore, while many studies have reported the impact of antiTNF- $\alpha$ on radiographic progression, limited data are available on the relationship between treatment agents and sagittal balance in AS.

Objectives: Limited data are available on the relationship between treatment agents and sagittal balance in AS. We investigated radiological features related to treatment agents and compared sagittal balance between patients treated with anti-tumour necrosis factor- $\alpha$ (anti-TNF- $\alpha$ ) or non-steroidal anti-inflammatory drugs (NSAIDs) and sulfasalazine.

Methods: We prospectively enrolled 133 consecutive AS patients. Patients were eligible for the trial if they were under medical treatment with the same treatment agents for at least 1 year. All patients were treated initially with NSAIDs and 